\title{
Making A Journey in Knowledge Management Strategy
}

\author{
John S. Edwards, Paul M. Collier, Duncan Shaw \\ Aston Business School, UK
}

\section{Contact details:}

Professor John S. Edwards, Aston Business School, Aston University, Aston Triangle, Birmingham, B4 7ET, U.K.

Telephone: $\quad+44(0) 121-3593611 \times 5029$

Fax: $\quad+44(0) 121-3595271$

E-mail: $\quad$ j.s.edwards@aston.ac.uk

Dr Paul M. Collier, Aston Business School, Aston University, Aston Triangle, Birmingham, B4 7ET, U.K.

Telephone: $\quad+44(0) 121-3593611 \times 5082$

E-mail: $\quad$ p.m.collier@aston.ac.uk

Dr Duncan Shaw, Aston Business School, Aston University, Aston Triangle, Birmingham, B4 7ET, U.K.

Telephone: $\quad+44(0) 121-3593611 \times 5078$

Fax: $\quad$ +44 (0)121-3595271

E-mail: $\quad$ d.a.shaw@aston.ac.uk

Keywords:

Knowledge management, facilitation, group decision support, knowledge management life cycle, knowledge champion. 


\title{
Making A Journey in Knowledge Management Strategy
}

\begin{abstract}
This paper reports results from an ongoing project examining what managers think about knowledge management in the context of their organisation. This was done in a facilitated computer-assisted group workshop environment. Here we compare the outcomes of workshops held for two relatively large UK organisations, one public sector, and one private. Our conclusions are that there are relatively few differences between the perceptions of these two groups of managers, and that these differences stem more from the stage of the knowledge management life cycle that the two organisations have reached, rather than the difference in context between public and private sector.
\end{abstract}

\section{Introduction}

It is generally agreed that knowledge management has human, process and technological aspects, and that the technological is - or at least should be - the least important of the three (Davenport and Prusak, 1998). It is also generally agreed that knowledge management in an organisation has to be firmly grounded in its culture (Amidon, 1998), so there can be no "one size fits all" way to "do" knowledge management. However, matters are further complicated by evidence that knowledge management is relatively transient, i.e. different at different times, even in the same organisation (Scarbrough et al., 1999).

In the research reported in this paper, we have taken an empirical approach, based on finding out what groups of staff in UK organisations think about knowledge 
management in their organisation. Typically most of these staff are "management", ranging from Board of Directors level downwards. Data has been collected in a workshop format, which enables a group understanding of knowledge management to be surfaced, rather than simply the separate understandings of individuals.

In this paper we concentrate on comparing and contrasting the results from two workshops, held with one public sector and one private sector organisation. Our intention is to examine whether this difference in context has any apparent effect on perceptions of knowledge management in those organisations.

The structure of the paper is as follows. We begin by reviewing relevant aspects of the theory of knowledge management, especially the process(es) of knowledge management, knowledge management in an organisational context, and its relationship with organisational learning.

We then describe the format of the workshops, and the methodology used in holding them. As far as we are aware, this is the first time that this particular technique, called Journey Making, has been applied to find out perceptions about knowledge management. Its previous use has been mainly in strategy development (Eden and Ackermann, 1998). A discussion of the results from the two workshops follows, and finally we draw some conclusions about the effectiveness of our approach and the influence of context in the two organisations studied. 


\section{Knowledge Management Theories}

There are many ways to look at both knowledge management and indeed knowledge itself. Space does not permit a full discussion of the precise meaning of knowledge in this paper, but see Edwards and Kidd (2003) for an introductory discussion. The following sections briefly review the more prominent ideas in the knowledge management literature that are relevant to this research project. The main (linked) themes are different types of knowledge, knowledge management as process, knowledge management in organisations, and the relationship between knowledge management in organisations and organisational learning.

\section{Different types of knowledge}

\section{Formal v informal knowledge}

One of the tensions apparent in the knowledge management literature is between the formal and the informal views of knowledge in the organisation. This is discussed in some detail by Fleck (1997). Fleck makes the point that information and knowledge are embedded in the working context, so that it is in fact very difficult to completely separate the formal from the informal. Nidumolu et al (2001) also examine the need for the practice of knowledge management to be suitably grounded in the organisation; they state that a fundamental purpose of managing knowledge must be to build some degree of shared context. This situatedness is a recurrent theme in the literature. Huber (2000) goes even further, pointing out that although a shared context is necessary for shared understanding, and thus knowledge transfer, it may still not be sufficient. 
Core and support knowledge.

The theory of business processes distinguishes between core and support processes (Earl, 1994). The core processes are the ones that make the organisation what it is; the ones performed directly for the external customers whom the organisation exists to serve. Support processes are typically for internal customers, and often "administrative" in nature. In so far as knowledge may be seen as linked to the business processes in an organisation, it may be helpful to make a similar distinction about the knowledge requirements. See Edwards and Kidd (2002). Core processes need to be done as well as possible. On this basis, any improvement in/addition to the organisation's core knowledge - the knowledge needed to perform the core processes - should produce a corresponding improvement in the organisation's overall performance. By contrast, supporting processes only need to be done "well enough". Thus beyond a certain point, improvements in/additions to the organisation's support knowledge will have little or no effect.

\section{Knowledge management as process}

There are many ways of looking at knowledge management in abstract. This paper adopts a "process" viewpoint - considering the process(es) involved in knowledge management and the activities that go to make up knowledge management. However, even from this particular viewpoint the literature still contains several different descriptions of the processes and activities, none of which seems to have gained common acceptance as yet. 
Amongst the best known are those of Wiig (1993), Holsapple and Joshi (1998), van der Spek and Spijkervet (1995), and Alavi (1997). Each of these presents a slightly different focus within the process viewpoint.

Wiig identifies four activities, with a focus on the knowledge itself:

- Creation and sourcing

- Compilation and transformation

- Dissemination

- Application and value realisation

Holsapple and Joshi present six activities, with a further breakdown into subactivities, the detail omitted here in order to save space. Their focus is on what the individual person does with or to the knowledge. The six activities are:

- Acquiring knowledge

- Selecting knowledge

- Internalizing knowledge

- Using knowledge

- Generating knowledge

- Externalising knowledge

Van der Spek and Spijkervet's list appears to focus very specifically on managing the knowledge. Their list runs:

- Creating knowledge

- Securing knowledge

- Distributing knowledge 
- Retrieving knowledge

Alavi's model also focuses on the knowledge, with four activities:

- Knowledge creation/acquisition

- Knowledge organisation/storage

- Knowledge distribution

- Knowledge application

A significant difference is that Alavi's model explicitly loops back from the final activity to the first one.

There are many other descriptions of the knowledge management process, from similar or indeed different viewpoints. A summary of several may be found in Beckman (1999). We believe it is most fruitful to acknowledge that there is no single most appropriate knowledge management process, and that each of these offers insights in its own way and in particular circumstances.

For the purposes of this research, we offer yet another view, because it has a slightly different focus again. It is based on a model we have presented before (Edwards, 1994). Here, there is an organisational focus on knowledge management, which is the appropriate one for our research. This model of the process distinguishes four basic activities:

- Acquire Knowledge

- Retain Knowledge

- Share Knowledge

- Use/Utilise Knowledge 
We deliberately do not define the precise meaning of each of these terms here, as from the empirical stance of our research we let the participants in the workshops decide what each term meant in their organisational context. Of the other models mentioned, ours is clearly most similar to that of Alavi, although ours explicitly incorporates retaining knowledge, which from an organisational perspective is often a major problem. In addition, Alavi's model was presented in the context of systems for knowledge management, rather than our interest of strategies for knowledge management.

\section{Knowledge Management in Organisations}

A substantial part of the knowledge management literature is devoted to knowledge management in the context of organisations. Knowledge management has been described as the process of creating, capturing and using knowledge to enhance organisational performance (Davenport and Prusak, 1998) (Bassi, 1998) (Parlby, 1997). In the majority of the knowledge management literature, the discussion takes place at the level of the whole organisation or corporation. Here we concentrate on two aspects: the lifecycle of knowledge management, and the need for knowledge champions.

Knowledge management lifecycles.

It seems reasonable to expect that the history and background of knowledge management in an organisation will form an important part of the relevant context, and indeed significantly affect future knowledge management activities. Although many authors implicitly appear to recognise the concept of a "knowledge management 
life cycle", somewhat surprisingly there is little detailed work to be found on this topic. One of the few exceptions is the paper by Alavi (1997) mentioned earlier, while perhaps the most detailed contribution is by the man who coined the phrase knowledge management, Karl Wiig himself (1999). This concentrates on the setting up phase for knowledge management in an organisation, although it does also provide a few pointers to later developments.

The need for knowledge champions.

As with most (if not all) other change initiatives, it has become clear that knowledge management will not succeed in an organisation unless it is backed by people with enough power and access to sufficient resources to make it work. The need for knowledge management to have these knowledge champions, and the qualities that they should have, are discussed at some length by Davenport and Prusak (1998) and by Skyrme and Amidon (1997). Duffy (1998) gives a more practical slant to the discussion.

\section{Knowledge Management and Organisational Learning}

\section{Top down v bottom up}

It is clear from the above-mentioned emphasis in the literature on the corporate or company level (Nonaka and Takeuchi, 1995) (Davenport and Prusak, 1998) that knowledge management must be strategic and therefore aligned more with top-down views and approaches. Without a strategic focus, the best that could be achieved would be isolated "islands of knowledge". By contrast, organisational learning must be organic, and bottom-up. As Peter Senge said (Fulmer and Keys, 1998) 
"Ultimately, you know that learning is occurring when human beings are able to do something they couldn't before".

However, neither is sufficient on its own. The relationship must therefore be complementary. Knowledge management must enable organisational learning, not just by giving it direction, but also by permitting, encouraging and facilitating it. Conversely, despite the "manager-driven" stance apparent in some of the literature, it is only through organisational learning that knowledge management can be made into a day-to-day reality in the organisation. There must be a will to work together and share knowledge from the top down, but the challenge is to make it work throughout the organisation. Nidimolu et al (2001) rightly describe knowledge in the firm as "emergent, distributed and resident in people, practice, artifacts and symbols".

\section{A pragmatic view}

So, the perspective taken in this paper (and indeed in the whole research project) is the pragmatic one that knowledge management is what people think it is. This is by no means the first research to adopt this perspective. Many similarly pragmatic surveys have been carried out, for example by Ruggles (1998), and by Alavi and Leidner (1999). There is a difference, however. Generally, the existing work either surveys several people in one organisation, such as that by Fruin (1997) at Toshiba or Becerra-Fernandez and Sabherwal (2001) at NASA's Kennedy Space Center, or one person from each of several organisations, such as the paper by Gold et al (2001). What these two approaches have in common is that their focus has always been on the individual, not on the group, even when the purpose of the study was to produce aggregate results. 
Our belief is that to understand knowledge management in context, it is crucial to study the understanding and beliefs of the group about knowledge management, not just the individuals in it. The only knowledge management article of which we aware that deals with groups as groups is by Roth and Styhre (2002). However, their interest is in achieving the sharing of knowledge content about one specific project, whereas ours is a more general consideration of knowledge management strategy in the organisation. In the following section we explain how we have gone about surfacing this group understanding.

\section{Workshop format and methodology}

\section{Facilitating group knowledge sharing}

In the research reported here, we assisted two organisations in addressing their knowledge management issues by harnessing the distributed knowledge of a group of managers in those organisations. For both organisations we harnessed the group members' knowledge through running computer-supported group workshops. The aim of running group workshops was to uncover the complexity of the issue of knowledge management strategy from the diverse perspectives of a range of organisational functions in order to develop a robust and feasible "roadmap" towards better knowledge management. We used group workshops in this study because groups have the advantage of having a wider range of knowledge about a situation than individuals. Hence the roadmap that is developed should be more likely to be robust and feasible, because we can synthesise the individual knowledge of, for example, the IT Director, the Sales Director and the Finance Director. The resulting outcomes are 
therefore more likely to meet the aims of the organisation as a whole, as well as those of each of the areas of the organisation represented in the group.

Using a computer-assisted group workshop environment to facilitate this interaction (rather than relying solely on verbal interaction) has certain advantages. For example,

- Only one person can speak at a time in a verbally interacting group (Gallupe et al., 1991). When using computer brainstorming software, all group members can share their opinions simultaneously and then structured, facilitated discussion can consider each issue in turn (Pinsonneault et al., 1999). Consequently, computer brainstorming is a very fast way of collecting a large number of diverse opinions (Dennis et al., 1996).

- Ideas are shared anonymously in electronic brainstorming. People might feel apprehensive about verbally sharing an opinion when they do not know what the reaction of other, possibly more senior, members in the group might be (Diehl and Stroebe, 1987). Thus it is expected that controversial, conflicting or supporting opinions can be shared more freely in the electronic support context (Cooper et al., 1996).

- Having ideas not being identified to any one person in electronic brainstorming enables the group discussion to consider the merits of (and rationale behind) each idea, without the prejudice of who contributed it.

- Group members might be less likely to experience groupthink in electronic brainstorming (Janis, 1982), because participants have the chance to express their ideas before they consider other peoples' opinions, therefore they have already formed their own opinions and might have attached some psychological commitment to them. The structured, facilitated discussion after 
the brainstorm is designed to explore the merits of different options systematically and in a balanced way, whilst also raising the awareness of the group members about alternative options.

The ultimate aim of these computer-supported group workshops was to enable group members to negotiate, and commit to, a set of unified outcomes (or action plan) which could be implemented to achieve the desired effects. The way this was achieved was by providing the group with a process which releases the thinking of each group member so they can share their knowledge (Shaw et al., 2001), and which effectively synthesises the group members different perspectives to build a rich understanding of the situation on which the outcome can be based (Eden and Ackermann, 1998).

\section{Methodology}

For both organisations the workshops were intended to help the group members consider the issue of knowledge management and design an implementable action plan which they thought would deliver better knowledge management for their organisation. This section will discuss: the methodology which was used to enable effective group communication and build an agreed action plan; the stages which the groups were often lead through to consider this issue in an holistic way; the selection of the participants; and the nature of the workshops we facilitated.

\section{Using a group decision support to consider knowledge management}

One facilitator led the workshops, facilitating the process of group interaction as well as managing how the content was captured during the group discussion. 
The methodology used is called JOURNEY Making (Eden and Ackermann, 1998), which is derived from JOint Understanding, Reflection and NEgotiation on strategY. As the name implies, its original use was for strategic planning. One of the intentions of this research has been to establish whether it can be equally effective for knowledge management strategy. Using JOURNEY Making, the group members are facilitated through a process of

- JOint Understanding - the group members are encouraged to share their ideas with the rest of the group during a computer-supported group brainstorm (through typing their ideas on an issue into a computer package - using about 8-10 words per idea).

- Reflection - asking the group members to integrate the ideas that have been shared into their own understanding of the issue i.e. asking them to reflect on their previously held views and reconsider these in the light of new information.

- NEgotiation - giving the group members the opportunity to verbally negotiate on the different opinions which have been shared, in order to converge views and generate a unified perspective of the situation, and generate shared commitment of all group members to the unified perspective to improve knowledge management.

- strateg $Y$ - potential processes for better knowledge management were identified throughout the group workshop. Each process had to contribute to the achievement of better knowledge management for the organisation. At the end of the workshop, and at suitable intervals during it, the group would 
review its progress by exploring the causal effect of the processes for achieving the goal of better knowledge management - in order to confirm their importance. The processes would be agreed upon (and thereby committed to) by the group members (or a sub-section of group members who had responsibility for that issue).

\section{Four stages to considering knowledge management in groups}

The process the group members used was focussed on considering knowledge management as an organisation-wide activity. The group strategic decision making methodology described above was employed to give structure to the complexity of the issues under consideration.

We have developed a generic four-stage process to guide the series of knowledge management workshops - this process was used in the two workshops detailed here. The process has been designed so that each stage builds on the previous stages. In the first stage, the group starts by considering "What knowledge informs our business?" The aim of this stage is to enable the participants to build a shared understanding of what knowledge they are actually referring to. The shared understanding built on this issue is the foundation on which the rest of the workshop is based.

In the second stage, the group considers "What knowledge management processes currently exist in our organisation?" This stage is further structured in terms of the acquisition, retention, sharing and utilisation model of the knowledge process put forward earlier in this paper. Participants consider each of these aspects of knowledge management in turn and so have the opportunity to share their opinions on each. This 
stage aims to give participants confidence that, however (in)formal or (in)effective they may be, they already have knowledge management processes in place in their organisation, and it prepares them for a gap analysis, in conjunction with the third stage.

The third stage involves the group members considering "What knowledge management processes should exist in our organisation?" again in terms of the acquisition, retention, sharing and utilisation of knowledge. Through exploring this question, participants think about the types of knowledge management processes which the organisation should consider building. In conjunction with the discussion around the second stage, this facilitates the identification of gaps where an organisation should have a process in place, but in fact does not.

The fourth stage explores "How do we (or should we) evaluate how good these processes actually are?" This stage encourages the participants to reflect upon what metrics should be used to evaluate how effective the organisation's knowledge management processes are. The aim of this session is to refine the implementation of the knowledge management process, so that any data collection process which needs to be in place for these metrics can be integrated into the initial development of the knowledge management process.

This four-stage process has been designed to enable the organisations to consider knowledge management in a structured, yet very flexible, environment. Structure is given to the workshop through this series of questions, and through building the participants' shared understanding of the situation through brainstorming and group 
discussion. Flexibility is given through the participants being able to decide the direction of the workshop during the workshop and through the sources of facilitated communication which are open to the participants.

\section{The selection of the participants}

In both workshops explored here, 9 participants attended. The number of participants will always depend on the number of stakeholder groups which need to be represented, but process limitations restrict attendance to about 15 participants with one facilitator. Participants were selected by the client organisation, in consultation with the facilitator. The two criteria were used to identify potential participants were,

1. That participants held responsibility for some aspect of knowledge management, and so it would be likely that these people would be involved in implementing the actions from the workshop. It is often useful to include the implementers of action plans in these workshops so they can feel that they developed the plan they are implementing, and can appreciate why they are implementing it. This can significantly help in the implementation.

2. That at least one group member was a Director (or someone of similar status) who would be able to commit the resources to perform actions which arose during the workshop. This was intended to prevent the scenario whereby no action plan can be finalised by the group because no-one has the authority to commit resources to implement the actions. 


\section{The JOURNEY Making set-up}

Each workshop lasted a full day, during which each of the four stages detailed above had its own dedicated brainstorm (or 'gathering session' in JOURNEY Making terminology) lasting between $1 \frac{1 / 4}{4}$ hours and $2 \frac{1}{2}$ hours. The ideas contributed during early gathering sessions were used to inform gathering sessions later in the day.

Participants were split into pairs, the pairings being changed for each brainstorm to enable different people to work together. This latter point assists creativity by offering the stimulus of a "new face" to work with. Each pair was given a laptop computer linked to a Local Area Network and running Group Explorer ${ }^{\mathrm{TM}}$, a computer brainstorming-like software package. In each session, a stimulus question (following the four stage process discussed above) was posed to the group members, and they were asked to consider the question and type into their laptop computer any ideas, thoughts, responses or opinions they had. The ideas which were shared were captured in 'group map' (as displayed in Figures 1 and 2), using Decision Explorer ${ }^{\mathrm{TM}}$ software.

The group map was then projected onto the public screen to enable group members to read the ideas which had been shared. Participants (and the facilitator with guidance from the participants) were then able to insert links (in the form of an arrow) between ideas on the map. An arrow indicates that a relationship exists between the issues contained in the two ideas. Hence the arrows can indicate, for example, what are the actions which need to be performed to achieve a certain result. The group map is used as a shared view on which the group can record their record their arguments and discussion. Using the arguments contained in the group map the group members are able to negotiate the best way forward in the situation i.e. to inform their 
consideration of what is the best action plan for improving knowledge management. Figures 1 and 2 show examples of the structure of group maps.

All of the gatherings in both workshops followed a similar format. Firstly, a session in which the ideas from other people were hidden from the participants and so they were working 'blind' - to enable their free thinking (Janis, 1982). Then a 'piggy-backing' session followed (Shaw et al., 2001) in which the ideas were displayed on a large projection screen. Hence once each member of the group had exhausted their own sharing of ideas during the blind session, they were able to look at the projection screen and see what contributions other people had made. They were encouraged to 'piggy-back' off the ideas they had read and share those new piggy-backed ideas - to enrich the group map with more ideas. Furthermore, some of the blind gathering sessions also employed a 'multiple stimuli' format. Here the group members were given four stimuli questions rather than one, which were shown on the public screen for them to consider. These pertained to the retention, acquisition, sharing and utilization of knowledge. Typically after the piggy-backing session about 70 ideas would be displayed on the public screen.

During the gathering the facilitator would be moving the ideas on the screen into content-related loose clusters to assist the participants in identifying the various clusters within the ideas. Hence, during the piggy-backing session, the participants would be more able to identify themes to which they had not already contributed any ideas, and share any new ideas they had. 
Following the piggy-backing session, the facilitator would structure a group discussion around (1) validating the clusters, (2) identifying any issues which were missing, (3) moving within each cluster to discuss each idea/issue in some depth, (4) understanding any relationships between the ideas (for example, so that participants could explore what the consequences and enablers of implementing knowledge management processes might be), (5) identify any potential actions which might need to be performed.

In some sessions, after part 5, the group electronically voted on which issues were the most important ones for their organisation. Typically this was done in terms of two dimensions: the potential benefit towards achieving the goals and the ease of implementation. Actions which have high potential benefit towards achieving the goals and which are thought to be easy to implement are generally ones which would be sensible to tackle first in order to make some quick-wins on improving knowledge management. This voting process enables the group members to appreciate which issues or processes (and so which actions) might be tackled first, and so the generation of an action plan would be underway. 


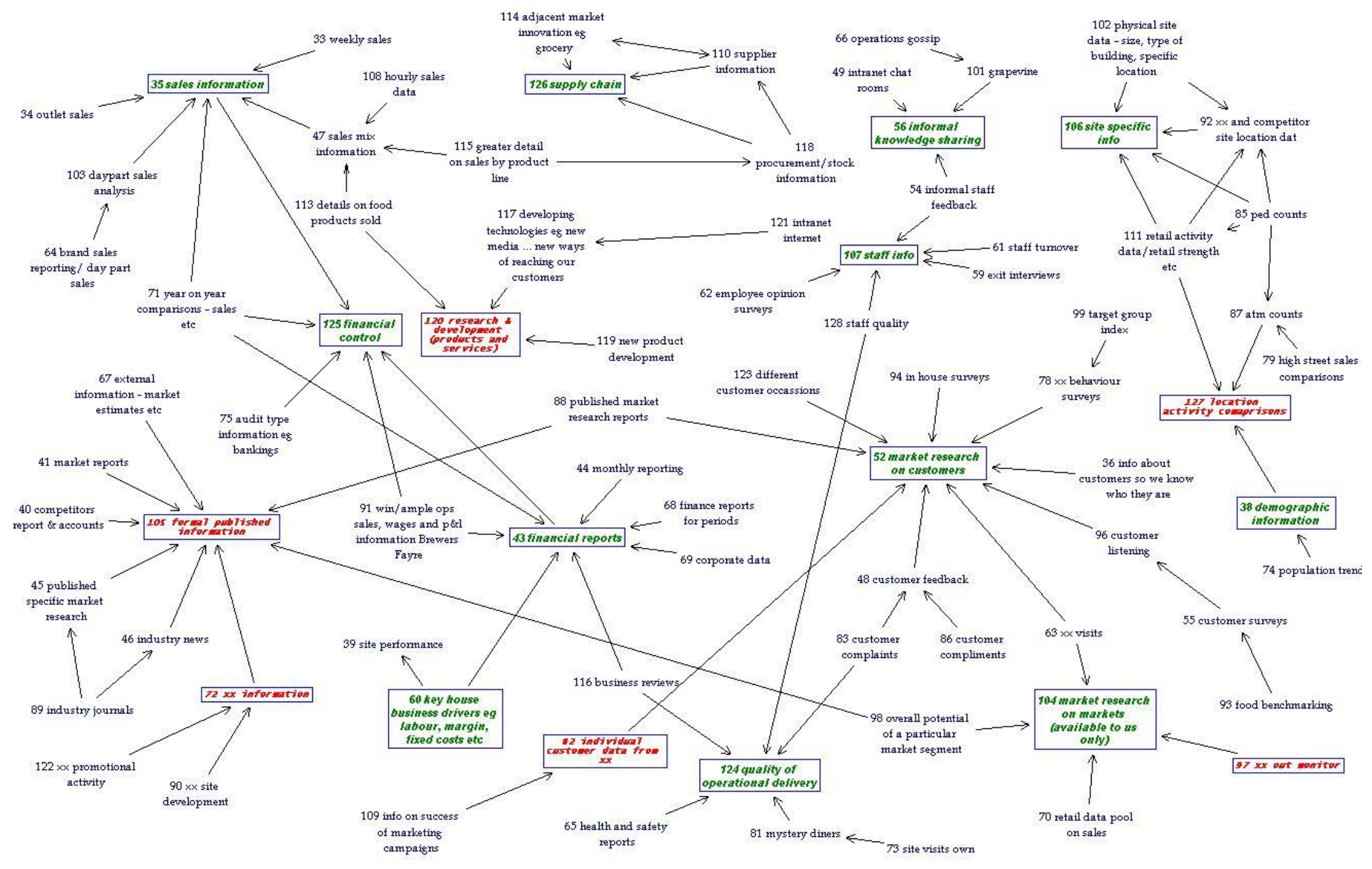

Figure 1: A group "road map" from the Zebra workshop 


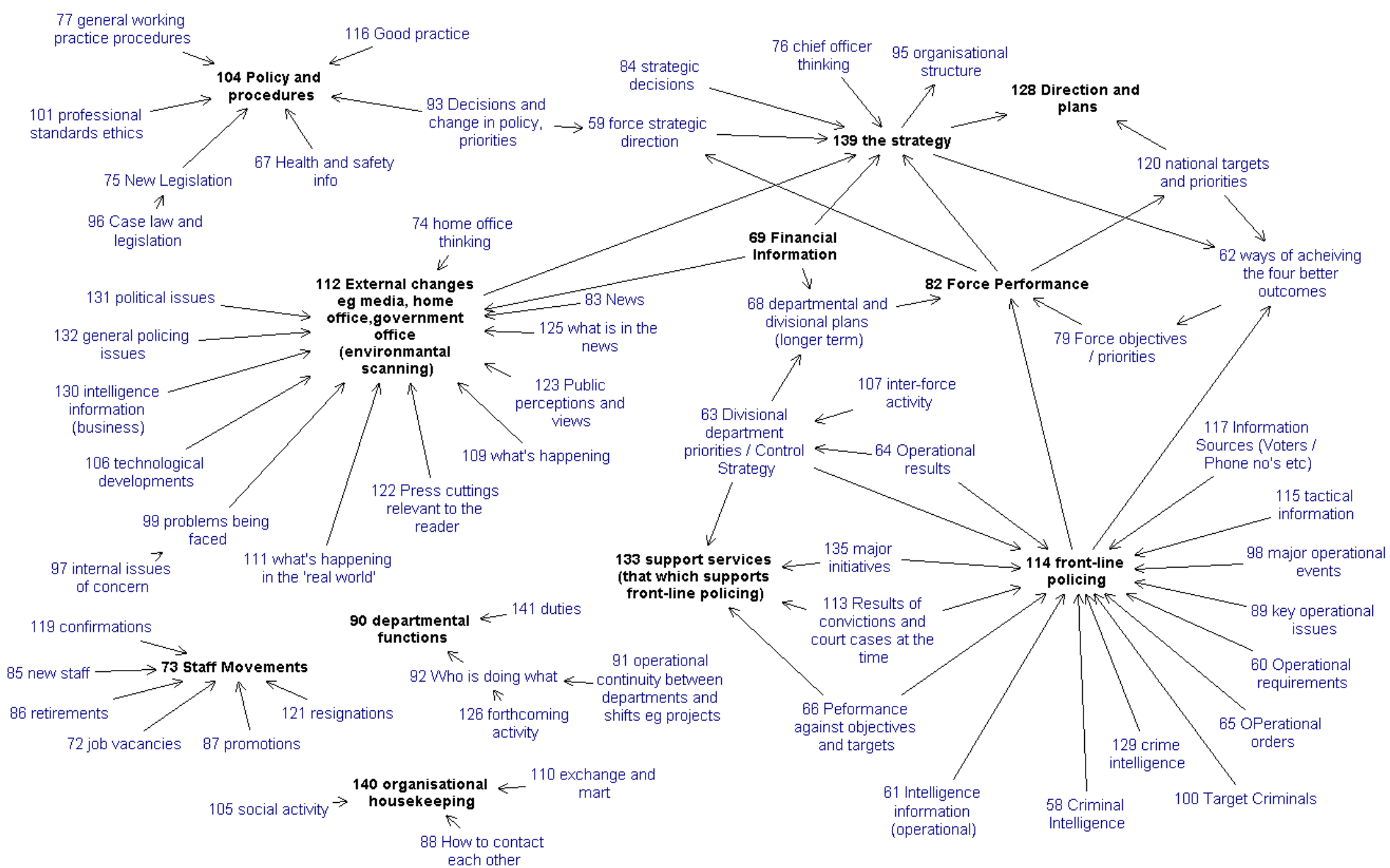

Figure 2: A group "road map" from the Police workshop 


\section{The workshops}

\section{Workshop 1: Zebra}

Zebra is the restaurants division of a listed PLC operating under about a dozen major brand names throughout the UK. Restaurant turnover was $£ 1$ billion in the last financial year.

Prior to the workshop, our prime contact, the Head of Consumer Insight, identified the importance of an achievable action plan as an outcome from the workshop, which he thought should have an open brief, although he was interested to find out

"Does Zebra think knowledge management is what other people think it is?"

Zebra had been working on knowledge management for some years before the workshop. Their attitude towards knowledge management was to see it as a logical development from data and information management. It was also seen as mainly concerning "Head Office" activities rather than those carried out in the restaurants (for example the skills of cooking or serving meals). Either of these two emphases could in fact have been the cause of the other, but it was not clear which might be the case.

There were nine participants in the workshop. Five were from the Planning \& Insight department (PID) including the director and the departmental head. Two were from the finance department involved in providing financial information to PID. The other two were a project analyst and a researcher. Two of the participants from PID were CIMA members (qualified accountants). 
In the first session, participants were asked the question "What knowledge informs Zebra's restaurant business?" Many ideas were generated. These were segregated into knowledge that was core to Zebra's business and supporting knowledge.

From Figure 1, the core knowledge can be categorised as sales, demographic and aggregated market research data, particularly at a site-specific level. Supporting knowledge included competitor information, and individual customer responses to surveys, promotions, etc. Information that was generally available to competitors was categorised as supporting rather than core. Financial information was regarded as core, particularly the "key business drivers ... labour, margin, fixed costs" and financial control reports.

In an aside during a review by participants of the clusters, one participant commented: "There is an under emphasis on finance [in the clusters] but we realise that these all link to finance. We would still be selling beer and running pubs if it wasn't for the City"

The second question we asked was "What processes are currently used to acquire, share, retain and utilise knowledge?" The first issue raised by the participants was the difference between information and knowledge. Three examples were given: the use of demographic information to make acquisitions; weekly news issued by email and Intranet; and a data warehouse that contained vast quantities of data for manipulation. The second issue raised was selective versus mass distribution. Each process was then identified as being carried out enough, not enough or too much, although "too much" 
did not necessarily mean that it should be reduced. The director of PID commented that

"What we do is the easy stuff ... the clever stuff is on the outside".

Another participant commented that

"We don't prioritise it from a cost perspective".

For the "not enough" group, the participants identified those that could be addressed in the short-term and those which required long-term projects.

A third issue that became apparent in the clustering was to what extent Zebra relied on formal or informal methods of communication. Again, the director of PID commented "Bits of knowledge don't give information, the trick is linking them all together".

The consensus was, in the words of one participant

"There is lots of information but not much knowledge".

One cluster revealed that too much reliance was being placed on informal chats, meetings, email, although formal meetings were also included in this list. Another, those processes that were not being done enough but could be addressed in the shortterm, included a variety of Intranet, telephone, pin-board, talking to staff, customers and the supply chain. Also evident in this "not enough" cluster were the purchase of data from consultancies, commissioned studies and defectors from competitors. However, using existing information and bringing together information for ad hoc reviews was also evident. The main difference between the two clusters seemed to be 
that the "too much" cluster was seen as passive while the "not enough" group were seen as active.

A third cluster was also "not enough" but which could only be addressed in the longterm. This cluster contained detailed sales history for trend analysis, site-based performance database, management information system, "cubes" of sales information for analysis and cross-functional teams. This third cluster emphasised information collected consistently, over time and produced in a common reporting format.

At this point, the Head of Consumer Insight noted that what the participants were recording was

"A corporate view of life ... we need to speak to a different-operationalview"

All participants in the workshop were in fact from "Head Office" departments. The researchers offered to deliver a workshop for operational staff at shop-floor level in order to compare and contrast shop floor with corporate views. At the time of writing, this has not yet been possible.

The researchers' third question was “What processes should be used to acquire, share, retain and utilise knowledge more effectively?" One of the first comments made by a participant was that

"Knowledge is only useful when it is shared"

Those processes that could be addressed in the short-term included using crossfunctional data, integrating that data and producing meaningful summaries - by brand 
- with less detail. Longer-term issues were more detailed sales mix and margin information, use of profiling rather than averages, common tools and wider availability of the ability to analyse sales data.

The main enablers that had to be addressed before any meaningful progress could be made were the need for a single source of all knowledge, based on standardised site technology

"So we are able to acquire consistent information in consistent ways".

However, participants recognised that this needed

"Buy in from the top down".

Standardised site technology to produce a single source of information was critical to obtain the long-term information that had been identified. However, overall the participants recognised that this was a long-term improvement that was dependent on a technological solution that was difficult to achieve. The participants identified the need for a

"Knowledge champion ... to champion and facilitate the process of communicating knowledge”.

The fourth question was "What measures are currently used, or should be used, in relation to the acquisition, sharing, retention and utilisation of knowledge?" in this workshop, this question assumed the participants had to develop a business case for resources to achieve the standardised site technology and the single source of information. The discussion focused on the information that could support such a business case. 
The Head of Consumer Insight asked rhetorically

"How do we know that knowledge leads to better success?"

to which the answer was

"Top down from the share price."

The participants commented that each brand had to achieve a $10 \%$ per annum sales growth and a 5\% per annum profit growth if it was to be retained.

Much information was identified as already being available, including share price, market share, like-for-like sales, balanced scorecard data, spend per head. However, the ability to respond by using knowledge and the synergies that were available from holding duplicate information were not known.

The participants, both informally after the workshop and via subsequent questionnaire and discussion appreciated the workshop. The workshop had crystallised their views and demonstrated the interdependencies. They had also produced a workable action plan. The maps built by the participants during the sessions accurately recorded the expressed views of the participants and their discussion about the issues. In particular the maps contained a record of the negotiated outcomes from that discussion, in the form of representing road maps of the actions which the participants had decided to implement.

It was interesting that while finance was not dominant explicitly during the workshop, it was implicit in much of the discussion, particularly in the first question where financial information was considered to be important (as shown on Figure 1 in the 
material around concept number 125, "financial control") and in the final question when the share price was emphasised. The desire to find a technological solution to a mass of inconsistent and often incompatible data from multiple sources required a substantial capital investment.

The participant-built maps enabled the researchers to gain deeper insight to the real issues of concern to the participants. The researchers were able to collect data on their views built by the participants themselves.

\section{Workshop 2: Police}

Police is an English police force with 2,400 police officers, 1,300 support staff and a budget of $£ 144$ million. Prior to the workshop, Police had increased the police levy (the portion of the council tax that pays for police services) by $33 \%$. Police had recently developed a new strategy around what they termed the "Four Better Outcomes". These were to: provide reassurance; reduce disorder and anti-social behaviour; reduce crime and increase detections; and reduce road casualties.

Prior to the workshop, management within Police were aware that they had never had any explicit knowledge management activity, nor did they have a knowledge management strategy as a whole. Indeed, the use of the term "knowledge" within Police raised issues in itself (see the discussion below). However, the intelligence-led policing approach (also discussed below) may mean that the operational aspects of knowledge management were less bad than those at Police Headquarters appeared to believe. 
Prior to the workshop, the Research \& Development Manager commented that “All we've got is knowledge but we're hopeless at managing it".

A new Director of Strategic Planning and Development (SPD) had been appointed to Police and a priority that had been established by the Chief Constable was to develop a communications strategy. A communications strategy was clearly seen as part of what we (the researchers) would call knowledge management. Two workshops were planned, the first concerned with communication within the organisation, the second with external stakeholders. Here we concentrate on the first (internal) workshop. The director of SPD wanted as an outcome of each workshop,

"A shared commitment to a shared plan".

One of the problems in researching a police force is the difficulty of bringing key people together. However the 9 participants included the SPD director, a police Superintendent (divisional commander), a traffic Inspector, two police constables, the Head of Information Systems, representatives of the Organisation Development Unit and a public relations officer.

The first workshop question was "What information needs to be communicated internally within Police?" In choosing this wording, we used the terminology preferred by the organisation. Knowledge is not a term in common use within Police at all. As far as we can judge, what "information" meant to the Police participants was no different to what "knowledge" meant to those from Zebra. A lot of ideas were provided very quickly by the participants (displayed in Figure 2), who recognised that many of these related to the Four Better Outcomes. The first issue that arose was the 
differing information requirements of the different structural units. Three different types of units were present in Police and each was represented at the workshop: the operational policing divisions; the Headquarters operational support units; and the Headquarters support departments. The first two of these provided front-line policing services, albeit one at a local level while the other was at a force-wide level. It became evident that while substantial detail was required at the operational level, more aggregated data and trends were more important at the force level. The main clusters of information were external changes (political, regulatory and press); frontline policing (driven by the Four Better Outcomes and national policing targets); and strategy (that was driven by the external cluster). Three organisational enablers were also identified: financial information, training and partnerships.

The researchers attempted to explore what information was core to Police and what was supporting (and so colour code some of the ideas in the same way as was done for Zebra in Figure 1). This became the second issue as it appeared that, in the words of the Head of IS:

"There is no core information that everyone needs to know."

The requirements of the three different types of unit mentioned earlier appeared to be substantially different.

The second question we asked was "What processes are currently used to acquire, share, retain and utilise information?" Again, participants contributed a lot of ideas but these were mechanisms rather than processes. These ideas fell into two distinct groups: formal, predominantly IT systems, and informal processes. An interesting theme was the use of "Dermot" as a source of information. Upon questioning the 
participants, who all knew Dermot, it was explained that Dermot was a Chief Superintendent who had an important informal role in addition to his formal role. The "Dermot" theme returned several times during the workshop in other gathering sessions, revealing the importance of informal communications to the participants.

Within these two broad groupings, there were a number of clusters. Although corporate IT systems fed into all these, other clusters included (for sharing) informal means, conferences, the canteen (culture), Intranet and radio (the primary means of communication for patrolling officers). Utilising information included intelligence-led policing processes, particularly tasking, supplemented by briefings. (Intelligence, for Police, has the same meaning as in the military context.) Retaining information was in part through manual filing systems, personal records and paperwork.

Several participants noted the reluctance by some police officers to use the available IT systems. The Head of IS said

"Because there are so many mechanisms, people ignore all of them ... The culture of the organisation is nobody told me",".

Reflecting the personal records and systems, the Chief Superintendent, a divisional commander, agreed that

"There are privately owned organisers and laptops that people shouldn't have ... these are a barrier to communications ... we don't have a means of delivery but people want to be force-fed".

The Director of SPD commented that 
“We don't have any processes ... or very limited processes ... we are totally dependent on individuals for acquiring knowledge ... sharing is limited ... this is evidence of why we are doing badly".

The third question was "What processes should be used to acquire, share, retain and utilise information?" After much discussion, this was broken down into three separate questions: How should we push information? How can willing people pull information? and How should we motivate reluctant people to pull information?, the latter reflecting the cultural barrier that had been identified earlier. A fourth question was added in anticipation of the second workshop to be held on external communications: What information should we, do we want to deliver to external parties? This question was important, the Chief Superintendent said, because it is

"The information I need to give them to help me to do my job"

recognising the importance of the community in helping to solve crimes and reduce disorder.

This third question resulted in a number of clusters: intelligence-led policing processes; meetings and presentations; written documents; telephone, radio, email and video; Intranet, IT systems, etc. The director of SPD noted that

$$
\begin{aligned}
& \text { "These are formal communications ... but we are heavily dependent on } \\
& \text { informal one-to-one communications. There is a plethora of informal } \\
& \text { processes ... to be effective we can't provide the quality of information for all } \\
& \text { these things". }
\end{aligned}
$$

Consequently, the workshop participants separately rated the mechanisms against the processes that would be most effective for corporate and operational communication. 
The Intranet was rated as most effective for corporate communications, followed by publications, IT systems, meetings and email. The most effective processes for operational purposes were intelligence-led policing followed by corporate IT systems, radio, Intranet and verbal. However, in discussion it was generally agreed that lots of information should be held on the Intranet. The participants agreed that

"If you only put the information in one place, that is where people will go to use it".

It was generally agreed that the way forward was to develop the Intranet operationally as well as corporately. There were various comments about how this could be made to happen, particularly given the existence of what the Chief Superintendent called "recalcitrant non-communicators". Some participants believed that it was a line manager's job to ensure their staff used the system. The Inspector commented "Every police constable has to access information at the beginning of their shift before going on patrol to do their job"

reflecting the intelligence-led tasking of police officers, following the "National Intelligence Model'. However, others considered that computer literacy was a barrier to the use of IT systems.

The fourth question was "How do we (or should we) evaluate the information that is on the Intranet?" The agenda for the workshop contained the same general evaluation question as the one addressed by the Zebra participants. However, the Police participants expressed the view that different methods of communicating knowledge/information for different purposes should be evaluated in different ways. They chose to concentrate on the method they had earlier rated as most effective for 
corporate communications, namely the Intranet. As our position is "knowledge management is what you think it is", we took the participants' lead and addressed this aspect of evaluation rather than the more general evaluation of knowledge processes (as agreed by Zebra participants).

The Head of IS defined the input-output-outcome model for an Intranet of "Inputs are the number of screens ... Outputs are the number of log-ons and screens accessed ... Outcomes are whether the piece of information has been communicated"

The Inspector identified the problems with measurement of inputs:

"The problem with forcing people to log off every time they use the system ... a whole room of people will use the data if one person is logged on ... the number of log-ons as a measure of how many people have used the system is meaningless ... we need to talk to the end-users - ask about routes and timers and targets",

the latter comment recognising the importance of the intelligence-led model.

The participants contributed a number of ideas for quantitative and qualitative aspects of evaluation, and again there were a number of clusters. Input measures were reflected in log-ons and hits, content and quality by user satisfaction and complaints. Functionality was represented by speed and ease of use and output was through knowledge checks. The outcomes that could be achieved were largely less time spent on briefings, and the achievement of the Four Better Outcomes evidenced by performance improvement. 
One police constable, a trainer, commented:

"They may spend more time using the Intranet than on briefings but they may be more effective when they go out on patrol".

This led to a consideration of the questions that had been identified earlier - the push and pull considerations to encourage greater use of formal information held on the Intranet. The clusters of ideas were around reluctant people being motivated to pull information if they understood the benefits. This was supported by a range of rewards and sanctions, greater use of activity analysis and the PDR - Police's performance appraisal system. The main theme here was making the Intranet fundamental to people's jobs. The Chief Superintendent added:

"We should make some things only available via the Intranet, for example expense payments, booking annual leave, claiming overtime”.

The final question was "What information should we deliver to the external environment?" in order to provide a starting point for the second workshop and because Police wanted to push some information to assist them. The clusters were around performance in relation to crime and detection to meet statutory requirements; crime prevention; reassurance; partnerships (for mutual benefit); education; and best practice. The Chief Superintendent summarised this as

"Delivering information to the external environment to prevent crime and to help to detect crime”. 
The group considered whether there were consistent processes in place to provide this information. Many had no consistent processes. The Head of IS added "All these things are done but there are no consistent processes. Things are done by different people at different times and in different ways".

The Director of SPD concluded the workshop by noting that

"The scale of information generated is enormous"

but that the group would be informed and involved as a communications strategy was developed.

\section{Discussion}

Although the two workshops were pilots for a continuing programme of research, there were common themes, despite one organisation being from each of the private and public sectors. In this section we review the workshops in the light of the theory described earlier.

\section{The role of technology}

In both organisations, there was general agreement that there was a great deal of knowledge, but that it was not well managed. This was largely because of the enormous variety of information that was available, held in widely different systems. In both organisations, information technology was seen as a key element in the solution. In Zebra this was through standardised site technology to produce a single source of information. In Police, this was predominantly through the Intranet as the delivery mechanism for a wide variety of data. However, both organisations appeared 
to appreciate that even if the technology was a necessary element of the solution, it was by no means sufficient on its own.

\section{Information and knowledge}

Perhaps the central issue that arose from the workshops was that of information versus knowledge. Participants in both workshops largely saw information as a commodity. Information did not appear to be valued at a corporate level, in contrast to the sense in which knowledge forms an integral part of an organisation's intellectual capital.

\section{Formal v informal knowledge}

In both organisations, the contrast between formal knowledge and informal knowledge was prevalent. Both recognised the importance of informal processes, but also held a desire to move to more formal, reliable and consistent ones. A difficulty was seen as being to retain the richness of the informal systems while adding the robustness and "shareability" of more formal ones.

\section{Core and support knowledge}

Here there was more of an apparent difference between the two organisations. The participants from Zebra, as mentioned above, found it relatively easy to identify what was core and what was supporting knowledge. In Police, by contrast, participants believed that the three different types of structural unit had fundamentally different core knowledge requirements. It is possible that the apparent unanimity in Zebra was because there were no operational level staff amongst the participants. 


\section{Knowledge management as process}

Participants clearly felt that the acquisition, sharing, retention, utilisation model was a satisfactory one on which to base their discussions. The general absence of formal processes in both organisations placed greater reliance on individuals, leading to a dependence on informal systems. The lack of consideration given at a senior management level to the processes necessary for knowledge management was marked in both organisations, particularly as both organisations were significantly knowledge-dependent for their success.

At a more detailed level, the main emphasis was on acquiring and sharing knowledge and information. There was less evidence of retaining and using the knowledge, or even information. In Zebra, its use was prospective in terms of having information that could lead to better location decisions and sales and profit growth, although this information was technology-dependent. In Police, the value of information had been recognised through the use of intelligence to drive police activity, although the use of this information through tasking and targeting was external to the technology.

\section{Knowledge Management life cycles}

The most significant difference between the workshops was in the commitment towards improvement. While the workshop participants in Zebra had that commitment, subsequent events revealed that the organisation did not share that commitment. By contrast, Police had recently appointed a Director of Strategic Planning and Development whose goal (given by the Chief Constable) was to develop a communications strategy. The simplest explanation is that each organisation was at 
a different stage of its knowledge management life cycle, Zebra being much further advanced than Police.

The need for knowledge champions

A key point in both workshops was the appreciation of the need for a knowledge champion in the organisation. The different stages of the knowledge management life cycle reached in the two organisations (discussed above) affected the nature of the discussion on this topic, but not the perceived importance of the role. In the Zebra workshop, much of one session was devoted to identifying potential knowledge champions, while in the Police workshop, the Director of SPD was clearly perceived by all participants to have been appointed to function as a knowledge champion.

\section{Top down v bottom up}

In both workshops, some participants expressed concern about whether the right people were at the workshop. In Police, the concern was whether operational police officers were adequately represented. This was a similar concern to that expressed during the Zebra workshop that managers or support staff were likely to provide a different perspective than those delivering frontline services. This suggests that care needs to be exercised in interpreting the results at different levels of the organisation and that there may be value in a series of workshops at different organisational levels within the same organisation. 


\section{The workshop methodology}

Some observations can also be made in relation to the methodology. In both workshops, the role of the facilitator was crucial in ensuring that the discussion remained focused and that the clustering of ideas generated represented the participants' views. From participant feedback and the researchers' own observations, we believe that the anonymity provided did encourage contributions that would not have been evident in the traditional brainstorming method. However, the methodology needs to be supplemented by more traditional note-taking as the 'big picture' issues can be lost in the detail of the mapping processes while some of the participants' asides, as reported here, provide a richer context of the progress of the workshop.

The maps themselves are a significant output of the workshops, providing a detailed record of the processes for acquiring, sharing, retaining and utilising knowledge and in particular demonstrating the inter-dependencies between clusters of knowledge and processes. The maps for these workshops were similar in terms of the number of ideas, but were very different in terms of the depth of their structuring, as can be seen by comparing Figures 1 and 2 . However, the maps are a means through which the participants JOintly Understand, Reflect and NEgotiate their knowledge management stratagY (i.e. "make their JOURNEY"). The purpose of these sessions is not to build a map - it is to develop feasible knowledge management strategy to implement. However, first indications (based on our very small sample) are that participants in these workshops about knowledge management generate ideas faster than do those in similar strategic planning workshops, but that the clustering and linking of the ideas takes longer. 
Both workshops went through a period of introspection during the middle of the day, concerning what the way forward for the rest of the day should be. In both cases the group eventually returned to the set agenda, having agreed that the processes of acquiring, sharing, retaining and utilising information that were currently used by the organisation needed to be followed by consideration of the processes that should be used by the organisation. This seemed to be an important element, methodologically speaking, in maintaining the ownership of each group in the workshop.

\section{Conclusions}

The JOURNEY Making methodology appears to be effective in helping participants to think about knowledge management in the context of their organisation and to develop an agreed action plan.

The overall outcomes of the two workshops reported here were very similar, in spite of their different contexts: one public sector organisation with a regional responsibility, one private sector organisation with a national presence. Three features were especially apparent:

- The emphasis in both cases was very much on acquiring knowledge (and to a lesser extent sharing knowledge) rather than retaining or utilising knowledge.

- Both groups clearly appreciated the existence of cultural and process-related process aspects of knowledge management, but found it much easier to think in terms of mechanisms, especially when considering possible actions in the context of their organisation. 
- In both workshops, a substantial period of the day was spent considering whether the programme originally proposed for the day needed to be changed for their context. Both times this was at the point where the focus moved from describing what currently happens to thinking about what should happen and how that might be achieved. In both cases, in the end the decision was made to return to the original programme.

Finally in terms of the workshops themselves, although the workshops appeared to be successful in securing commitment within the group of participants, in order to progress knowledge management in the organisation, commitment outside the group is also vital. This is where the two workshops differed most, this commitment being much more apparent in Police than in Zebra. We believe that this is because Zebra was much further along the knowledge management life cycle than Police at the time when the respective workshops were held. Indeed, it is possible that Zebra's apparent focus on "Head Office" rather than operational level knowledge management, both in this workshop and previously, may in itself be one of the reasons why commitment from other senior managers was at best lukewarm. The importance of the organisational context in which knowledge management is being considered seems therefore to be crucial.

From the viewpoint of the JOURNEY Making approach, two differences between the contexts of these knowledge management workshops and previous strategic planning workshops were apparent. The first was the nature of the links that participants made between the concepts in the maps. In the context of the knowledge management workshops, these links usually denoted interdependence of some kind, instead of the causal relationships of the strategic planning maps. The second was that the 
production of an action plan seemed less important for knowledge management than for strategy development. We hypothesise that this is because knowledge management is more related to process, and strategy development to outcome.

\section{Acknowledgement}

This research was funded by CIMA, the Chartered Institute of Management Accountants in the UK.

\section{References}

Alavi, M. (1997) Knowledge management and knowledge management systems. Presented at ICIS 97, The Eighteenth International Conference on Information Systems, Atlanta, Georgia, 1997.

Alavi, M. and Leidner, D. E. (1999) Knowledge management systems: issues, challenges and benefits. Communications of the AIS, 1, (Article 7).

Amidon, D. M. (1998) Blueprint for 21st century innovation management. Journal of Knowledge Management, 2, (1), 23-31.

Bassi, L. (1998) Harnessing the power of intellectual capital. The Journal of Applied Manufacturing Systems, (Summer), 29-35.

Becerra-Fernandez, I. and Sabherwal, R. (2001) Organizational knowledge management: A contingency perspective. Journal of Management Information Systems, 18, (1), 23-55.

Beckman, T. J. (1999) The current state of knowledge management. In Knowledge Management Handbook (Ed, Liebowitz, J.) CRC Press, Boca Raton, pp. 1-1 1-22.

Cooper, W. H., Gallupe, R. B., Pollard, S. and Cadsby, J. (1996) Flaming face-toface: The dis-inhibiting role of anonymity in electronic brainstorming groups. Working Paper 96-12. School of Business, Queen's University, Ontario, Canada.

Davenport, T. H. and Prusak, L. (1998) Working knowledge : how organizations manage what they know. Harvard Business School Press, Boston, Mass.

Dennis, A. R., Haley, B. J. and Vandenberg, R. J. (1996) A meta-analysis of effectiveness, efficiency, and participant satisfaction in group support systems. Presented at International Conference on Information Systems, Cleveland, Ohio, 1996.

Diehl, M. and Stroebe, W. (1987) Productivity loss in brainstorming groups: Toward the solution of a riddle. Journal of Personality and Social Psychology, 53, 497-509.

Duffy, D. (1998) In CIO, Vol. 12, pp. 66-71. 
Earl, M. J. (1994) The new and the old of business process redesign. The Journal of Strategic Information Systems, 3, (1), 5-22.

Eden, C. and Ackermann, F. (1998) Making Strategy: The Journey of Strategic Management. Sage, London.

Edwards, J. S. (1994) Knowledge Management and Management Knowledge. Internal working paper. Aston University, Birmingham.

Edwards, J. S. and Kidd, J. B. (2002) Bridging the gap from the general to the specific by linking knowledge management to business processes. In Knowledge and Business Process Management (Ed, Hlupic, V.) Idea Group, Hershey PA.

Edwards, J. S. and Kidd, J. B. (2003) Knowledge Management sans frontières. Journal of the Operational Research Society, to appear.

Fleck, J. (1997) Contingent knowledge and technology development. Technology Analysis \& Strategic Management, 9, (4), 383-397.

Fruin, W. M. (1997) Knowledge works : managing intellectual capital at Toshiba. Oxford University Press, New York.

Fulmer, R. M. and Keys, J. B. (1998) A conversation with Peter Senge: new developments in organizational learning. Organizational Dynamics, 27, (2), 33-42.

Gallupe, R. B., Bastianutti, L. M. and Cooper, W. H. (1991) Unblocking brainstorms. Journal of Applied Psychology, 76, 137-142.

Gold, A. H., Malhotra, A. and Segars, A. H. (2001) Knowledge management: An organizational capabilities perspective. Journal of Management Information Systems, 18, (1), 185-214.

Holsapple, C. W. and Joshi, K. D. (1998) Knowledge management: a three fold framework. Research Paper 118. College of Business and Economics, University of Kentucky.

Huber, G. P. (2000) Transferring Sticky Knowledge: Suggested solutions and needed studies. In Proceedings of Knowledge Management beyond the Hype: Looking towards the new millennium. Proceedings of KMAC 2000 (Ed, Kidd, J. B.) Operational Research Society, Birmingham, pp. 12-22.

Janis, I. L. (1982) Groupthink. Houghton Mifflin Company, Boston.

Nidumolu, S. R., Subramani, M. and Aldrich, A. (2001) Situated learning and the situated knowledge web: Exploring the ground beneath knowledge management. Journal of Management Information Systems, 18, (1), 115-150.

Nonaka, I. and Takeuchi, H. (1995) The knowledge-creating company, how Japanese companies create the dynamics of innovation. Oxford University Press, New York and Oxford.

Parlby, D. (1997) KPMG Management Consulting.

Pinsonneault, A., Barki, H., Gallupe, R. B. and Hoppen, N. (1999) Electronic brainstorming: The illusion of productivity. Information Systems Research, 10, 110-133.

Roth, J. and Styhre, A. (2002) Knowledge facilitation at AstraZeneca. Presented at European Academy of Management Conference, Stockholm, Sweden, May 9$11,2002$.

Ruggles, R. (1998) The state of the notion: Knowledge management in practice. California Management Review, 40, (3), 80-89.

Scarbrough, H., Swan, J. and Preston, J. (1999) Knowledge Management and the Learning Organisation: A review of the literature. Institute of Personnel and Development., London. 
Shaw, D., Ackermann, F. and Eden, C. (2001) Sharing ideas in groups A research report on electronic group brainstorming for real-world workshops. Working Paper RP0113. Aston Business School, Birmingham, U.K.

Skyrme, D. and Amidon, D. M. (1997) Creating the Knowledge-Based Business. Business Intelligence, London.

van der Spek, R. and Spijkervet, A. (1995) Kenniscentrum CIBIT, Utrecht, Netherlands.

Wiig, K. M. (1993) Knowledge Management Foundations: Thinking about Thinking how people and organizations create, represent and use knowledge. Schema Press, Arlington, TX.

Wiig, K. M. (1999) Introducing knowledge management into the enterprise. In Knowledge Management Handbook (Ed, Leibowitz, J.) CRC Press, Boca Raton, pp. 3-1 - 3-41. 